NBER WORKING PAPER SERIES

\title{
COMPETITION, INNOVATION AND GROWTH WITH LIMITED COMMITMENT
}

\author{
Ramon Marimon \\ Vincenzo Quadrini \\ Working Paper 12474 \\ http://www.nber.org/papers/w12474
}

\author{
NATIONAL BUREAU OF ECONOMIC RESEARCH \\ 1050 Massachusetts Avenue \\ Cambridge, MA 02138 \\ August 2006
}

\begin{abstract}
We would like to thank Francesco Caselli, Hugo Hopenhayn, Boyan Jovanovic, Narayana Kocherlachota, Omar Licandro, Michele Boldrin, Stephen Parente and seminar participants at CEMFI, CEPR Macroeconomic Symposium in Cyprus, London School of Economics, ITAM, Monetary Conference at Banco of Portugal, NBER Summer Institute, SED meeting in Budapest, Universitat Pompeu Fabra, University of Porto, University of Southern California, University of Toronto and World Congress in London. Marimon acknowledges support from Ente Luigi Einaudi, Fundacion BBVA and Ministerio de Educacion y Ciencia. Quadrini acknowledges support from the National Science Foundation. The views expressed herein are those of the author(s) and do not necessarily reflect the views of the National Bureau of Economic Research.
\end{abstract}

(C2006 by Ramon Marimon and Vincenzo Quadrini. All rights reserved. Short sections of text, not to exceed two paragraphs, may be quoted without explicit permission provided that full credit, including ( $)$ notice, is given to the source. 
Competition, Innovation and Growth with Limited Commitment

Ramon Marimon and Vincenzo Quadrini

NBER Working Paper No. 12474

August 2006

JEL No. L14, L16, O4

\title{
$\underline{\text { ABSTRACT }}$
}

We study how barriers to competition---such as restrictions to business start-up and strict enforcement of covenants or IPR---affect the investment in knowledge capital when contracts are not enforceable. These barriers lower the competition for human capital and reduce the incentive to accumulate knowledge. We show in a dynamic general equilibrium model that this mechanism has the potential to account for significant cross-country income inequality.

\author{
Ramon Marimon \\ CREI - Pompeu Fabra \\ Ramon Trias Fargas, 25-27 \\ 08005 Barcelona \\ SPAIN \\ and NBER \\ $\underline{\text { rms2@mcyt.es }}$ \\ Vincenzo Quadrini \\ Department of Finance and Business Economics \\ Marshall School of Business \\ University of Southern California \\ 701 Exposition Boulevard \\ Los Angeles, CA 90089 \\ and NBER \\ quadrini@usc.edu
}




\section{Introduction}

Sustained levels of income and growth rely on innovation and adoption of new technologies, which in turn require the accumulation of human capital. This is clearly visible in modern technologies - such as information technologies, biotechnologies and nanotechnologies - where skilled human capital or knowledge is a factor of production highly complementary to physical capital. Because the owners of physical capital - 'investors' - are often distinct from the owner of knowledge capital — 'innovators' - the design of contractual arrangements are necessary to provide the right incentives.

Several factors limit the enforceability of these arrangements. First, knowledge capital can not be used as a collateral and innovators may quit the firm to pursue other projects. Second, advance payments to the innovator are not incentive compatible if the accumulation of knowledge from the innovator requires effort. Third, once the innovation process has been completed, the investor may renege on the payments promised to the innovator.

The severity of these contractual frictions depend on the value that knowledge capital has outside the firm. This value may be curtailed by several barriers. One barrier acts through the imposition of restrictions to the creation of new firms which typically have more incentive to innovate than incumbent firms. Another barrier is a tight enforcement of covenants, precluding innovators to use their acquired knowledge in a different firm. A similar barrier is a stringent system of intellectual property rights.

The evolution of the computer industry exemplifies these effects. As Bresnahan \& Malerba (2002) emphasize, such an industry has gone through different technological stages (from the main frames to PCs and the Internet). Knowledge in this particular industry was geographically spread among many countries including those in Europe. Yet, the United States has been persistently the industry leader. According to them, such dominance can be explained by "...the existence of a large body of technical expertise in universities and the generally supportive environment for new firm formation in the United States", Bresnahan \& Malerba (2002, page 69).

While lower barriers to business start up may have favored the computer leadership of the United States, the different enforcement of covenantsand informational linkages across firms - may have determined the shift of regional leadership within the United States. As argued by Saxenian (1996), Gilson (1999) and Hyde (2003), Silicon Valley dominates over Route 128 due to a Californian legal and social tradition of not enforcing post-employment 
covenants, resulting in high labor mobility and knowledge spillovers.

This paper formalizes these ideas and addresses the question of whether competition for innovators affects income levels through the accumulation of knowledge. We use a dynamic general equilibrium model where innovators can not be bound to the firm and therefore their mobility is determined by other legal and social barriers. Our main result is that the degree of competition for knowledge capital is a determinant factor for innovation when neither the investor nor the innovator can commit to long-term contracts.

The intuition for these findings is simple. Competition for knowledge capital creates an outside value for the innovator that is used as a threat against the investor's attempt to renegotiate the promised payments. Barriers to entry or mobility reduce the outside value and, in absence of commitment from the investor, they reduce the incentive of the innovator to accumulate knowledge. Without barriers, innovators may even over-accumulate knowledge to keep the outside value high. An incumbent firm could prevent the over-accumulation by making advance payments. However, advance payments are not incentive-compatible if contracts are not enforceable also for the innovator. It is in this sense that the double-side limited commitment plays a central role.

Our results are first illustrated in a simple two-stage model which is then extended to a dynamic infinite horizon set-up. The parametrization of the model allows us to quantify the contribution of the cost of business start-up in generating cross-country income inequality. We then show that other barriers to mobility, such as the strict enforcement of covenants, can be incorporated in the model to account for regional differences.

The paper relates to three strands of literature. First is the labor literature that studies the accumulation of skills within the firm (e.g., Acemoglu (1997), Acemoglu \& Pischke (1999), Acemoglu \& Shimer (1999)). In this literature, higher outside values worsen the hold-up problem and lead to lower accumulation of skills. In our framework, instead, higher outside values increase human capital investment.

Second is the growth literature, starting with the pioneering work of Romer (1990, 1993), that studies the economics of ideas and the link between competition and growth (e.g., Greenwood \& Jovanovic (1990), Aghion \& Griffith (2005), Boldrin \& Levine (2006)). Whether free entry enhances innovation has been a major topic of research and debate. Most of the literature has focused on market structure and product market competition. In particular, on the ability to gain market shares and appropriate the returns 
to R\&D, as in Aghion, Bloom, Blundell, Griffith, \& Howitt (2005). More closely related to our work is Aghion, Blundell, Griffith, Howitt, \& Prantl (2004). They show - both, theoretically and empirically - that 'firm entry' spurs innovation in technologically advanced sectors as firms try to 'escape competition' while Acemoglu, Aghion, \& Zilibotti (2002) show that barriers to entry are especially costly for economies closer to the technology frontier. We focus on the less studied - but we think, empirically relevant - dimension of 'human capital' competition. By emphasizing the role of barriers to mobility, our work also relates to the literature that, building on the work of economic historians (e.g., Mokyr (1990)), emphasizes the role of barriers to riches in slowing growth (Parente \& Prescott (2002)).

The third branch of literature is on dynamic contracts with enforcement constraints, as in Marcet \& Marimon (1992). A common assumption in this literature is that default or repudiation leads to market exclusion, while in our framework barriers to mobility matter precisely because there is no market exclusion (Kocherlachota (1996) and Cooley, Marimon, \& Quadrini (2004) are exceptions). Many of the existing papers conclude that a stronger commitment enhances income and growth. In our framework, instead, income and growth can be enhanced with specific forms of limited commitment.

\section{Cross-country evidence on barriers to business start-up}

Before describing the theoretical framework, we present here some crosscountry data suggesting a relation between the cost of business start-upthat in our theory acts as a barrier to knowledge mobility - and cross-country income. Our theory is broader than simply capturing the impact of barriers to business start-up. Here we focus on these particular data because of its availability.

A recent publication from the World Bank (2005) provides data on the quality of the business environment for a cross-section of countries, including proxies for the barriers to business start-up. There are three main variables. The first is the 'cost to start a new business'. This is the average pecuniary cost needed to set-up a corporation in the country, in percentage of the country per-capita income. ${ }^{1}$ The second proxy is the "number of bureaucratic

\footnotetext{
${ }^{1}$ The normalization of the cost of business start-up by the level of per-capita income better captures the importance of barriers to business start-up than the absolute dollar cost. What is relevant is the comparison between the cost of business start-up and the
} 
procedures' that need to be filed before starting a new business. The third proxy is the average 'length of time' required to start a new business.

Figure 1 plots the level of per-capita GDP in 2004 against these three indicators, where all variables are in log. All panels show a strong negative correlation indicating that the set-up of a new business is more costly and cumbersome in poor countries.

The cost of business start-up is also negatively correlated with economic growth. To show this, we regress the average growth in per-capita GDP from 2000 to 2004 (the five more recent years) to the cost of business startup. We also include the 1999 per-capita GDP to control for the initial level of development. We would like to emphasize that the goal of these regressions is not to establish a causation but only to highlight the key correlations that motivate our study. The estimation results, with $t$-statistics in parenthesis, are reported in Table 1.

Table 1: Cost of business start-up and growth.

\begin{tabular}{lccc}
\hline & $\begin{array}{c}\text { Initial } \\
\text { Cer-Capita } \\
\text { GDP }\end{array}$ & $\begin{array}{c}\text { Cost } \\
\text { of Business } \\
\text { Start-Up }\end{array}$ \\
\hline $\begin{array}{l}\text { Coefficients } \\
t \text {-Statistics }\end{array}$ & 15.55 & -1.16 & -1.04 \\
$R$-square & $(5.01)$ & $(-3.81)$ & $(-4.92)$ \\
$N$. of countries & 0.150 & \\
NOTES: Dependent variable is the average annual growth rate in \\
per-capita GDP for the five year period 2000-2004. Initial Per- \\
Capita GDP is the log of per-capita GDP in 1999. The cost of \\
business start-up is in percentage of the per-capital Gross National \\
Income as reported in Doing Business in 2005 (also in log)
\end{tabular}

As can be seen from the table, the cost of business start-up is negatively associated with growth even if we control for the level of economic development. Therefore, countries with lower barriers to entry tend to experience faster growth. This finding is robust to the choice of alternative years to compute the average growth rate. The other proxies for barriers to entryspecifically, the number of procedures and the time required to start a new

value of creating a business. Although the dollar cost is on average higher in advanced economies, the value of a new business is also likely to be higher. 
Figure 1: Barriers to business start-up and level of development.
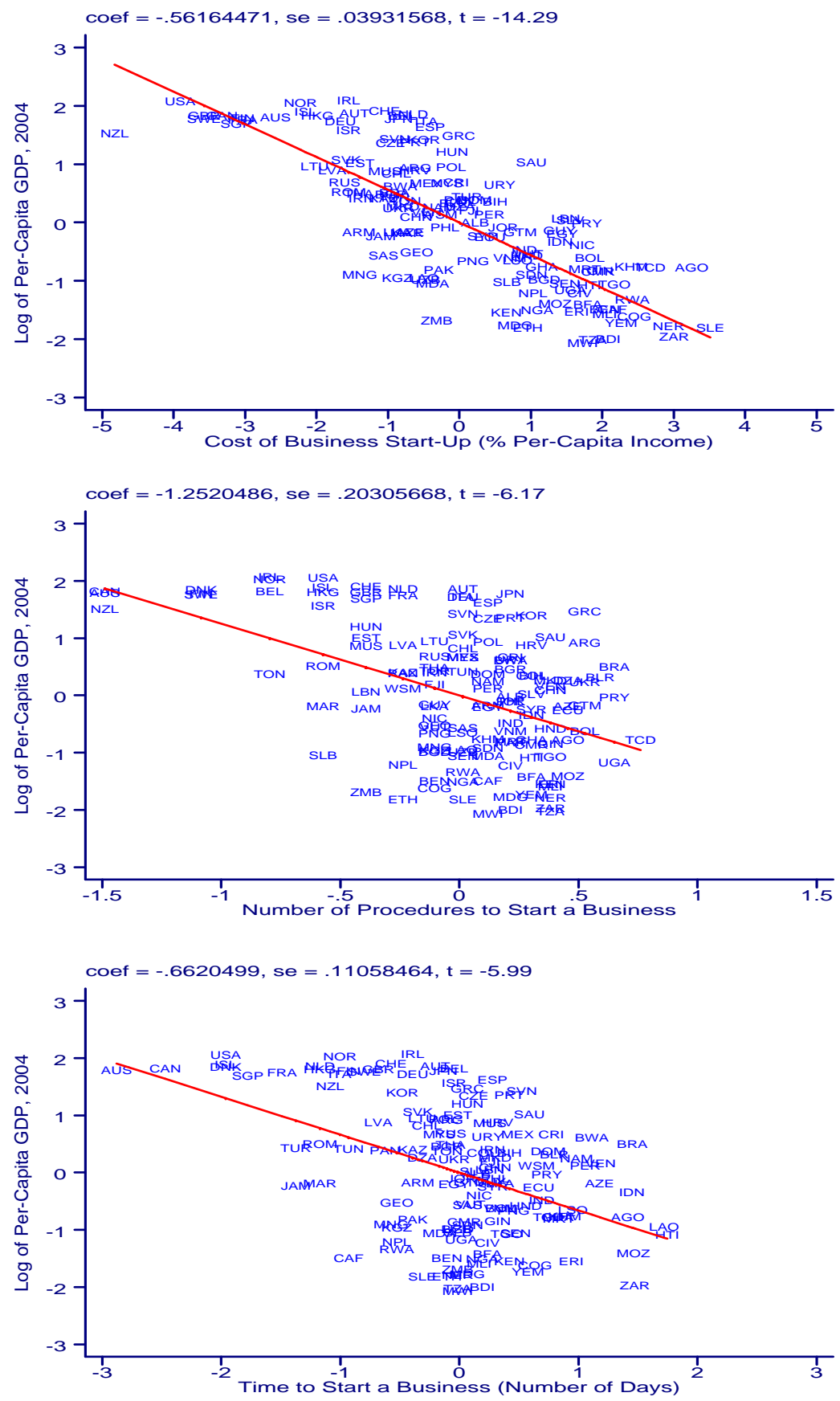
business - are also negatively correlated with growth but they are not statistically significant at conventional levels.

To summarize, the general picture portrayed by the data is that economic development and growth is negatively associated with the cost of starting a business. We have presented simple correlations which, of course, do not imply causation. In the following section we present a model where barriers to entry and, more generally, to knowledge capital mobility, lead to lower income and growth. We will return to the cross country data presented here in the quantitative analysis of Section 6.

\section{The model}

There are two types of agents in the economy: a continuum of 'investors' of total mass $m>1$ and a continuum of 'innovators' of total mass 1 . Therefore, innovators are in short supply relatively to investors. Investors own all the physical capital, $k_{t}$, and innovators are the only holders of knowledge capital, $h_{t}$. The lifetime utilities for investors and innovators are, respectively, $\sum_{t=0}^{\infty} \beta^{t} c_{t}$ and $\sum_{t=0}^{\infty} \beta^{t}\left(c_{t}-e_{t}\right)$, where $c_{t}$ is consumption and $e_{t}$ is the effort to accumulate human capital or knowledge as specified below.

Innovators do not save. This assumption should be interpreted as an approximation to the case in which innovators discount more heavily than investors. Risk neutrality implies that the equilibrium interest rate is equal to the intertemporal discount rate, that is, $r=1 / \beta-1$.

Firms are owned by investors who need the management and innovation skills of innovators. We will use the terms 'investor' and 'firm' interchangeably throughout the paper. The production function is:

$$
y_{t}=z_{t}^{1-\alpha} k_{t}^{\alpha}
$$

where $z_{t}$ is the level of technology and $k_{t}$ is the capital chosen at time $t-1$.

The variable $z_{t}$ changes over time as the firm adopts new technologies. The key assumption is that the implementation of more advanced technologies requires higher knowledge. An innovator with knowledge $h_{t}$ has the ability to implement and run any technology $z_{t} \leq h_{t}$.

The investment in knowledge, $h_{t+1}-h_{t}$, requires effort from the innovator. Because of possible leakage or spillover effects, we allow the effort to depend on the economy-wide knowledge $H_{t}$. The effort cost function is denoted by:

$$
e_{t}=\varphi\left(h_{t}, h_{t+1} ; H_{t}\right)
$$


which is strictly decreasing in $H_{t}$ and $h_{t}$, strictly increasing and convex in $h_{t+1}$, and satisfies $\varphi\left(h_{t}, h_{t} ; H_{t}\right)>0$. It is further assumed that the function is homogeneous of degree $\rho>1$. With this restriction the model generates only long-term differences in income levels, and therefore, this is a semiendogenous growth model as in Jones (1995). The analysis can be easily extended to $\rho=1$, in which case we would have long-term growth differences. ${ }^{2}$

Physical capital is technology-specific. When the firm innovates, only part of the existing capital is usable with the new technology. Capital obsolescence increases with the degree of innovation. This is formalized by assuming that the depreciation rate increases with the size of the innovation, that is,

$$
\delta_{t}=\delta \cdot\left(\frac{z_{t+1}}{z_{t}}\right)
$$

Because of capital obsolescence, there is an asymmetry between incumbent firms - whose capital depreciates with the adoption of more advanced technologies - and new firms that, without capital in place, have greater incentive to innovate (Arrow's 'replacement effect').

Firms remain productive with probability $p$. Whether a firm survives is revealed after the investment in knowledge. This assumption guarantees that, after the investment, the mass of innovators is larger than incumbent (surviving) firms. This will avoid some technical issues as we will emphasize later. To facilitate the analysis we first assume that $p$ is very close to 1 and, in the characterization of the individual problems, we will ignore it. The general case with any value of $p$ will be characterized in Appendix G.

Competitive structure and barriers: In each period there is a walrasian market for innovators. The market opens twice: before and after the accumulation of knowledge. Both incumbents and new firms can participate. The effective competition for innovators created by potential new firms is limited by different types of barriers. For the moment, we consider only barriers to business start-up. The analysis of other barriers, such as the strict enforcement of covenants, will be conducted in Section 7 with similar results.

\footnotetext{
${ }^{2}$ The model can be interpreted as a detrended version of an economy that grows at the exogenous rate dictated by the worldwide knowledge. Let $\bar{H}_{t}$ be the worldwide knowledge growing at rate $\bar{g}$, with the effort cost function, $e_{t}=\tilde{\varphi}\left(h_{t}, h_{t+1} ; H_{t}, \bar{H}_{t}\right)$, homogeneous of degree 1. After normalizing all variables by $\bar{H}_{t}$, the effort cost function can be rewritten as $\varphi\left(h_{t}, h_{t+1} ; H_{t}\right)$, which is homogeneous of degree $\rho<1$.
} 
Barriers to entry are modeled as a deadweight cost, $\tau \cdot h_{t+1}$, proportional to the initial level of knowledge $h_{t+1}$. We would like to emphasize that the key results of the paper are robust to alternative specifications of the entry cost. Our choice is only motivated by its analytical convenience. ${ }^{3}$

\section{One-period model}

Before studying the general model with infinitely lived agents, we first consider a simplified version with only one period, which provides an easier intuition for the key results of the paper. The analysis of the infinite horizon model, however, is still important because it allows us to derive the initial conditions endogenously as steady state values and, more generally, it is better suited for the quantitative application of Section 6 .

There are two stages: before and after the investment in knowledge. The states at the beginning of period are $h_{0}$ and $k_{0}$. After making the investment decisions, $h_{1}$ and $k_{1}$, the firm generates output $y_{1}=z_{1}^{1{ }^{\alpha}} k_{1}^{\alpha}$ in the second stage. Because $z_{1}=h_{1}$, the output can also be written as $y_{1}=h_{1}^{1-\alpha} k_{1}^{\alpha}$. In this simple version of the model we assume that physical capital fully depreciates after production. The innovator receives a payment $w$ at the end of the period, and therefore, after the choice of $h_{1}$. Payments before the choice of $h_{1}$ are not incentive-compatible because of the limited enforcement of contracts for the innovator. With only one period, we can abstract from discounting and ignore the leakage or spillover effects.

The timing of the model is as follows: The firm starts with initial states $h_{0}$ and $k_{0}$. At this stage the innovator decides whether to stay or quit the firm. If the innovator quits, she can be hired either by an incumbent firm or by a new firm (funded by a new investor). If the innovator decides to stay, she will choose the new knowledge $h_{1}$, implement the technology $z_{1}=h_{1}$ and the investor provides the funds to accumulate the new physical capital $k_{1}$. After the investment decision, the firm pays $w$. At this stage the innovator can still quit, but she cannot change the level of knowledge $h_{1}$. The investor is the residual claimant of the firm's output.

\footnotetext{
${ }^{3}$ For example, we could assume that the cost is proportional to the initial capital $k_{t+1}$ or to the initial output $h_{t+1}^{1-\alpha} k_{t+1}^{\alpha}$ or to the discounted flows of outputs. The basic theory and results also apply when the entry cost is a fixed payment. The assumption of proportionality allows for a continuous impact of $\tau$ while a fixed cost would have an impact only after it has reached the prohibitive level.
} 


\subsection{Equilibrium with one-side limited commitment}

We first characterize the equilibrium when at least one of the parties, either the investor or the innovator, commit to the contract. The commitment of one party is sufficient for the implementation of the optimal investment. As we will see, it is the limited commitment of both parties (double-side limited enforcement) that induces a deviation from the optimal investment. We start with the characterization of the equilibrium when only the investor commits. It will then be trivial to show that this is also the allocation when contracts are enforceable for both parties or for the innovator only.

With investor's commitment, all variables are chosen at the beginning of the period to maximize the total surplus, subject to the enforcement constraints for the innovator. Let $D\left(h_{0}\right)$ be the repudiation value for the innovator before choosing $h_{1}$ and $\widehat{D}\left(h_{1}\right)$ the repudiation value after choosing $h_{1}$. These functions are endogenous and will be derived below as the values that the innovator would get by quitting the firm. From now on we will use the hat sign to denote the functions that are defined after the investment in knowledge (second stage). The participation of the innovator requires that the value of staying is greater than the repudiation value before and after the knowledge investment, that is,

$$
\begin{aligned}
w-\varphi\left(h_{0}, h_{1}\right) & \geq D\left(h_{0}\right) \\
w & \geq \widehat{D}\left(h_{1}\right)
\end{aligned}
$$

As we will show, the second constraint is always satisfied if the first constraint is satisfied. Therefore, in the derivation of the optimal policy, we can neglect the second constraint and write the optimization problem as:

$$
\begin{aligned}
& \max _{h_{1}, k_{1}, w}\left\{-\varphi\left(h_{0}, h_{1}\right)-k_{1}+\left[1-\delta \cdot\left(\frac{h_{1}}{h_{0}}\right)\right] k_{0}+h_{1}^{1-\alpha} k_{1}^{\alpha}\right\} \\
& \quad \text { s.t. } \\
& w-\varphi\left(h_{0}, h_{1}\right) \geq D\left(h_{0}\right) \\
& -w-k_{1}+\left[1-\delta \cdot\left(\frac{h_{1}}{h_{0}}\right)\right] k_{0}+h_{1}^{1-\alpha} k_{1}^{\alpha} \geq 0
\end{aligned}
$$

where the second constraint is the participation condition for the investor. 
A quick glance at the optimization problem reveals that the investment choices are independent of the payment $w$. The value of $w$ is determined by the division of the surplus, as specified below.

To determine the repudiation value before the choice of $h_{1}$, we have to solve for the optimal investment when the innovator quits the firm. The innovator could be hired by an incumbent or a new firm, whoever makes the best offer. Because an incumbent firm never offers more than a new firm, it becomes relevant to determine the offer made by a potential entrant. This is derived from the contractual problem solved by a new firm, that is:

$$
S\left(h_{0}\right)=\max _{h_{1}, k_{1}, w}\left\{-\varphi\left(h_{0}, h_{1}\right)-\tau h_{1}-k_{1}+h_{1}^{1-\alpha} k_{1}^{\alpha}\right\}
$$

\section{s.t.}

$$
\begin{gathered}
w-\varphi\left(h_{0}, h_{1}\right) \geq D\left(h_{0}\right) \\
-w-\tau h_{1}-k_{1}+h_{1}^{1-\alpha} k_{1}^{\alpha} \geq 0
\end{gathered}
$$

Because of competition among potential entrants, an innovator that quits for a new firm will get the whole surplus generated by the new firm, that is, $S\left(h_{0}\right)$. This implies that $D\left(h_{0}\right)=S\left(h_{0}\right)$ and, if the innovator stays with the incumbent firm, the payment $w$ must be at least $\varphi\left(h_{0}, h_{1}\right)+S\left(h_{0}\right)$. Formally, the participation constraint in problem (1) becomes $w-\varphi\left(h_{0}, h_{1}\right) \geq S\left(h_{0}\right)$.

Problems (1) and (2) show the different incentive to invest for an incumbent versus a new firm. On the one hand, new firms do not have any physical capital and innovations do not generate capital obsolescence. On the other, they must pay the entry cost $\tau h_{1}$, which discourages knowledge and capital accumulation. This is clearly shown by the first order conditions in problems (1) and (2), with respect to $h_{1}$. These can be written as:

$$
\begin{aligned}
& (1-\alpha)\left(\frac{k_{1}}{h_{1}}\right)^{\alpha}=\varphi_{h_{1}}\left(h_{0}, h_{1}\right)+\delta \cdot\left(\frac{k_{0}}{h_{0}}\right) \\
& (1-\alpha)\left(\frac{k_{1}}{h_{1}}\right)^{\alpha}=\varphi_{h_{1}}\left(h_{0}, h_{1}\right)+\tau
\end{aligned}
$$

where the subscripts denote derivatives. The left-hand-side terms are the marginal productivity of knowledge. The right-hand-side terms are the marginal costs. For an incumbent firm, the marginal cost derives from the effort 
incurred by the innovator plus the obsolescence of physical capital. For a new firm the obsolescence cost is replaced by the entry cost.

Let $h_{1}^{\text {Old }}$ be the optimal knowledge investment of an incumbent (old) firm and $h_{1}^{\text {New }}$ the optimal investment of a new firm. The following proposition formalizes the relation between barriers to entry and knowledge investment.

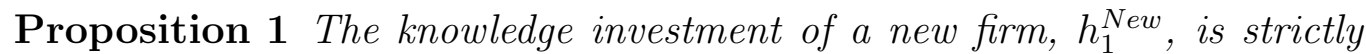
decreasing in the entry cost $\tau$ and there exists $\bar{\tau}>0$ such that $h_{1}^{\text {New }}=h_{1}^{\text {Old }}$.

Proof 1 The first order condition for the choice of $k_{1}$ is $\alpha\left(k_{1} / h_{1}\right)^{\alpha-1}=1$ for both incumbent and new firms. Using this condition, (3) and (4) become:

$$
\begin{aligned}
& (1-\alpha) \alpha^{\frac{\alpha}{1-\alpha}}=\varphi_{h_{1}}\left(h_{0}, h_{1}^{\text {Old }}\right)+\delta \cdot\left(\frac{k_{0}}{h_{0}}\right) \\
& (1-\alpha) \alpha^{\frac{\alpha}{1-\alpha}}=\varphi_{h_{1}}\left(h_{0}, h_{1}^{\text {New }}\right)+\tau
\end{aligned}
$$

The proposition follows directly from these two conditions.

Q.E.D.

In equilibrium there is no entrance of new firms at the beginning of the period and the investment in knowledge is $h_{1}=h_{1}^{\text {Old }}$. The potential entrance of new firms only affects the payment received by the innovator. In the second stage there will be the entrance of new firms because some incumbent firms exit (although the number is negligible because $p \simeq 1$ ). However, the level of knowledge cannot be changed at this stage.

Before continuing we show that the equilibrium investment does not change if both parties (or the investor only) commit. Because $h_{1}^{\text {Old }}$ maximizes the total surplus, this must also the equilibrium investment if both parties commit to the contract. The same result applies if it is the innovator who commits. In this case the investor can renege the promised payments after the investment in knowledge. However, this problem can be solved by making the payment $w$ before the investment in knowledge. As long as the contract is enforceable for the innovator, there is no risk that she runs away with the cash or she does not exercise the effort to accumulate knowledge.

\subsection{Equilibrium with double-side limited commitment}

We want to show first that, when the investor can not commit to fulfill his promises, he will renegotiate the contract after the choice of $h_{1}$. To see this, 
we must derive the value that the innovator would get by quitting the firm when her knowledge has already been chosen to be $h_{1}$. This is the surplus generated by a new firm, hiring the innovator, defined as:

$$
\begin{aligned}
\widehat{S}\left(h_{1}\right)=\max _{k_{1}, w}\left\{-\tau h_{1}-k_{1}+h_{1}^{1-\alpha} k_{1}^{\alpha}\right\} \\
\text { s.t. } \\
w \geq \widehat{D}\left(h_{1}\right) \\
-w-\tau h_{1}-k_{1}+h_{1}^{1-\alpha} k_{1}^{\alpha} \geq 0
\end{aligned}
$$

Because of competition, the innovator gets the whole surplus, that is, $\widehat{D}\left(h_{1}\right)=\widehat{S}\left(h_{1}\right)$. An incumbent firm will renegotiate the promised payment $w$ if this is higher than $\widehat{S}\left(h_{1}\right)$. The renegotiation threat after the accumulation of knowledge is credible because the firm can always replace the current innovator with other innovators. This could be either an innovator still employed by an incumbent (surviving) firm, or an innovator who separated from an exiting firm. Because in the second stage there are only $p<1$ firms that are still alive but the mass of innovators is 1 , innovators are in the long side of the market (relatively to the number of incumbent firms). This implies that they only get the reservation value. ${ }^{4}$

Based on the above discussion, we have that the innovator will receive $w=\widehat{S}\left(h_{1}\right)$ and the total utility from staying with the firm is:

$$
-\varphi\left(h_{0}, h_{1}\right)+w=-\varphi\left(h_{0}, h_{1}\right)+\widehat{S}\left(h_{1}\right)
$$

If instead the innovator quits at the beginning of the period, she will get the surplus $S\left(h_{0}\right)$ generated by the new firm, that is,

$$
S\left(h_{0}\right)=\max _{h}\left\{-\varphi\left(h_{0}, h\right)+\widehat{S}(h)\right\}=-\varphi\left(h_{0}, h_{1}^{\text {New }}\right)+\widehat{S}\left(h_{1}^{\text {New }}\right)
$$

Equations (6) and (7) show that the value of quitting at the beginning of the period, $S\left(h_{0}\right)$, is greater than the value of staying, as long as $h_{1} \neq$ $h_{1}^{\text {New }}$. Therefore, the innovator will quit unless the firm agrees to the same

\footnotetext{
${ }^{4}$ We have ignored this probability in the contractual problem because we are looking at the limiting case of $p \simeq 1$. The analysis with $p<1$ will be done in Appendix G.
} 
knowledge investment chosen by a new entrant firm, that is, $h_{1}=h_{1}^{N e w}$. In this way the innovator keeps the repudiation value high and prevents the firm from renegotiating. ${ }^{5}$

Proposition 2 Suppose that all firms have the same initial states $\left(k_{0}, h_{0}\right)$. Then there is a unique equilibrium with aggregate knowledge $H_{1}=h_{1}^{\text {New }}$.

Proof 2 See Appendix A.

Because $h_{1}^{\text {New }}$ is decreasing in $\tau$ (see Proposition 1), the accumulation of knowledge decreases with the cost of entry. Therefore, with double-side limited enforcement, there is a negative correlation between barriers to entry and the accumulation of knowledge.

To summarize, greater competition (lower barriers to entry) leads to higher investment in knowledge. Because the investment is determined by the optimality condition of new firms, such level is not necessarily efficient for incumbent firms. In particular, if $\tau$ is small, incumbent firms accumulate too much knowledge. The presence of spillovers, however, may make the higher investment socially desirable. We will re-introduce the spillovers in the analysis of the infinite horizon model.

Remarks: There are two points to be emphasized. First, the importance of $p<1$. If $p$ was equal to 1 , we would have the same number of innovators as incumbent firms in the second stage. This may lead to multiple equilibria. Each firm would renegotiate if all other firms renegotiate. But each firm would not individually renegotiate if all other firms do not renegotiate because there are no innovators willing to move for a lower pay. The assumption of a positive probability of exit, although small, eliminates this multiplicity because there is at least one innovator who separated from the original firm and is willing to accept a lower payment.

The second point is that output sharing is equivalent to promised payments. Thus, the assumption of limited enforcement for the investor also applies to the promise of a share of output.

\footnotetext{
${ }^{5}$ This proves that, if the enforcement constraint for the innovator is satisfied at the beginning of the period, it is also satisfied after the investment in knowledge.
} 


\section{The infinite horizon model}

In this section we generalize the model to an infinite horizon set-up. We first characterize the equilibrium with commitment and then we turn to the case of double-side limited commitment. The comparison between these two environments clarifies the importance of double-side limited enforcement for barriers to entry to affect the accumulation of knowledge. To present the results more compactly, we relegate most of the technical analysis and proofs to the appendix.

Before continuing, it will be convenient to define the gross output function, inclusive of undepreciated capital, as follows:

$$
\pi\left(h_{t}, k_{t}, h_{t+1}\right)=\left[1-\delta \cdot\left(\frac{h_{t+1}}{h_{t}}\right)\right] k_{t}+h_{t}^{1-\alpha} k_{t}^{\alpha}
$$

In writing this expression we assume that the firm uses the best technology implementable by the innovator, that is, $z_{t}=h_{t}$. It is easy to show that the choice of $z_{t}<h_{t}$ is never optimal.

\subsection{Equilibrium with one-side commitment}

We start characterizing the environment where only the investor commits. As in the one-period model, the equilibrium allocation with investor's commitment is equivalent to the allocation achieved when the innovator commits (with or without commitment from the investor). What changes the equilibrium outcome is the limited commitment of both.

The analysis of the infinite horizon model will concentrate on steady state equilibria. Therefore, in the analysis that follows we will ignore the aggregate states as an explicit argument of the value functions.

Although in equilibrium there is no entrance of firms (more precisely the number of firms entering is negligible), we still need to solve for the dynamics of a new firm in order to determine the outside or repudiation value for the innovator. Even though the analysis is limited to steady states, newly created firms do experience a transition to the long-term level of physical and knowledge capital.

Let $V\left(h_{t}\right)$ be the repudiation value for the innovator at the beginning of the period, before investing in knowledge. This is the value that an innovator with knowledge $h_{t}$ would receive by quitting the current employer 
and switching to a new firm. Similarly, let $\widehat{V}\left(h_{t+1}\right)$ be the value of quitting after the investment in knowledge, and therefore, after exercising effort. The optimization problem solved by a new firm that hires an innovator with knowledge capital $h_{0}$ at the beginning of period 0 is:

$$
\begin{array}{ll}
V\left(h_{0}\right)=\max _{\left\{w_{t}, k_{t+1}, h_{t+1}\right\}_{t=0}^{\infty}} \sum_{t=0}^{\infty} \beta^{t}\left[w_{t}-\varphi\left(h_{t}, h_{t+1} ; H\right)\right] & \\
\text { subject to } & \\
\sum_{j=t}^{\infty} \beta^{j-t}\left[w_{j}-\varphi\left(h_{j}, h_{j+1} ; H\right)\right] \geq V\left(h_{t}\right), & \text { for } t>0 \\
w_{t}+\sum_{j=t+1}^{\infty} \beta^{j-t}\left[w_{j}-\varphi\left(h_{j}, h_{j+1} ; H\right)\right] \geq \widehat{V}\left(h_{t+1}\right), & \text { for } t \geq 0 \\
-\tau h_{1}-w_{0}-k_{1}+\sum_{t=1}^{\infty} \beta^{t}\left[\pi\left(h_{t}, k_{t}, h_{t+1}\right)-w_{t}-k_{t+1}\right] \geq 0 &
\end{array}
$$

The optimal contract maximizes the value for the innovator, subject to the enforcement constraints for the innovator (the first two conditions) and the participation constraint for the investor (non-negative profits). The problem is also subject to a non-negative constraint for $w_{t}$.

For an innovator hired by a new firm at time 0 , after the investment in knowledge, the value of the contract is:

$$
\widehat{V}\left(h_{1}\right)=\max _{\left\{w_{t}, k_{t+1}, h_{t+2}\right\}_{t=0}^{\infty}}\left\{w_{0}+\sum_{t=1}^{\infty} \beta^{t}\left[w_{t}-\varphi\left(h_{t}, h_{t+1} ; H\right)\right]\right\}
$$

subject to the same constraints as problem (9).

The key difference respect to the problem solved by a new firm entering at the beginning of the period, is that the effort to accumulate knowledge has already been exercised and $h_{1}$ is given at this point. Hence, the current flow of utility for the innovator is only $w_{0}$. This also explains why the choice of knowledge starts in the next period.

Appendix B derives the first order conditions for problem (9). Because of the entry cost and the obsolescence of physical capital, the optimality conditions in the entry period, that is, $t=0$, is different from the optimality 
conditions in subsequent periods. The first order conditions at $t=0$ are:

$$
\begin{aligned}
& V\left(h_{t}\right) \leq w_{t}-\varphi\left(h_{t}, h_{t+1} ; H\right)+\beta V\left(h_{t+1}\right) \\
& \beta \pi_{2}\left(h_{t+1}, k_{t+1}, h_{t+1}\right)=1 \\
& \tau+\varphi_{2}\left(h_{t}, h_{t+1} ; H\right)=\beta\left[\pi_{1}\left(h_{t+1}, k_{t+1}, h_{t+2}\right)-\varphi_{1}\left(h_{t+1}, h_{t+2} ; H\right)\right]
\end{aligned}
$$

where subscripts denote derivatives.

The first condition says that the value of quitting the current employer cannot be bigger than the current flow of utility plus the discounted value of quitting next period. The second condition equalizes the gross marginal return of capital to its marginal cost, which is 1 . The last condition equalizes the marginal cost to accumulate knowledge to the discounted value of its return (greater production and lower cost of future knowledge investment).

The first order conditions after entering, that is, for $t>0$, are similar to the ones derived above with the exception of condition (13), which becomes:

$-\pi_{3}\left(h_{t}, k_{t}, h_{t+1}\right)+\varphi_{2}\left(h_{t}, h_{t+1} ; H\right)=\beta\left[\pi_{1}\left(h_{t+1}, k_{t+1}, h_{t+2}\right)-\varphi_{1}\left(h_{t+1}, h_{t+2} ; H\right)\right]$

Conditions (13) and (14) show the asymmetry between new and incumbent firms. While the marginal benefit from investing in knowledge (the right-hand-side) is the same, the marginal cost (the left-hand-side) differs. For new firms this includes the entry cost, $\tau$. For incumbent firms the entry cost is replaced by the depreciation of physical capital, $-\pi_{3}\left(h_{t}, k_{t}, h_{t+1}\right)$.

We can now characterize the steady state equilibrium. Because in equilibrium there is no entrance, all firms have the economy-wide knowledge $H$. The convergence to the economy-wide average is the result of the spillovers in the accumulation of knowledge. Because of this, firms with lower than average knowledge tend to invest more. Thanks to the complementarity of knowledge and physical capital, all firms accumulate the economy-wide level of physical capital. The values of $H$ and $K$ are determined by conditions (13) and (14) after imposing the steady state conditions, that is:

$$
\begin{aligned}
& \beta \pi_{2}(H, K, H)=1 \\
& -\pi_{3}(H, K, H)+\varphi_{2}(H, H ; H)=\beta\left[\pi_{1}(H, K, H)-\varphi_{1}(H, H ; H)\right]
\end{aligned}
$$


Appendix $\mathrm{C}$ shows that the steady state values of $H$ and $K$ are unique. After solving for $H$ and $K$, we can then solve for the steady state payment $w$. This requires us to solve for the whole transition experienced by a 'new firm', as characterized by the first order conditions (11)-(14). Even if in equilibrium there are neither quitting innovators nor entrance of firms, the value of $w$ depends on the value of a new firm $V(H)$.

Conditions (15) and (16) also reveal that the entry cost $\tau$ does not affect the steady state values of $K$ and $H$. We will see in the next section that this does not hold when there is limited commitment also from the investor. ${ }^{6}$

\subsection{Equilibrium with double-side limited commitment}

Let's start with the enforcement constraints imposed on the previous problem with investor's commitment. These constraints, before and after the investment in knowledge, can be written as:

$$
\begin{aligned}
& \sum_{j=t}^{\infty} \beta^{j-t}\left[w_{j}-\varphi\left(h_{j}, h_{j+1} ; H\right)\right] \geq V\left(h_{t}\right) \\
& \sum_{j=t}^{\infty} \beta^{j-t}\left[w_{j}-\varphi\left(h_{j}, h_{j+1} ; H\right)\right] \geq-\varphi\left(h_{t}, h_{t+1} ; H\right)+\widehat{V}\left(h_{t+1}\right)
\end{aligned}
$$

Appendix B shows that $V\left(h_{t}\right)>-\varphi\left(h_{t}, h_{t+1} ; H\right)+\widehat{V}\left(h_{t+1}\right)$. This implies that the investor has an ex-post incentive to renegotiate the promised payments. That is, the lack of credibility of the one-period economy is recurrent in the infinite horizon economy

Let $h_{t+1}^{\text {New }}=f\left(h_{t}\right)$ be the investment in knowledge chosen by a new firm in the entry period, when the initial knowledge of the innovator is $h_{t}$ and the investor does not commit to the contract. The next proposition establishes that, with double-side limited commitment, incumbent firms choose the same knowledge investment as new firms.

Proposition 3 With double-side limited commitment, the knowledge investment chosen by an incumbent firm is equal to the knowledge investment chosen by a new firm, that is, $h_{t+1}^{\text {Old }}=h_{t+1}^{\text {New }}=f\left(h_{t}\right)$.

\footnotetext{
${ }^{6}$ As we will show in Appendix G, when $p$ is not arbitrarily close to 1 , the steady state with investor's commitment does depend on $\tau$. In this case the limited enforcement from the investor amplifies the negative effects of barriers to entry.
} 
Proof 3 See Appendix D.

Since the firm can renegotiate the promised payments after the investment in knowledge, the innovator would not stay unless the firm agrees to the same knowledge investment chosen by a new firm. In this way, the innovator keeps the outside value high and prevents the firm from renegotiating.

Let $J\left(h_{t}\right)$ be the repudiation value for the innovator when neither the investor nor the innovator commit to the contract. Furthermore, let $\widehat{J}\left(h_{t+1}\right)$ be the corresponding value after the investment in knowledge. Given the above proposition, the optimization problem for a new firm, started at $t=0$, can be written as:

$$
\begin{aligned}
& J\left(h_{0}\right)=\max _{h_{1},\left\{w_{t}, k_{t+1}\right\}_{t=0}^{\infty}} \sum_{t=0}^{\infty} \beta^{t}\left[w_{t}-\varphi\left(h_{t}, h_{t+1} ; H\right)\right] \\
& \text { subject to } \\
& \sum_{j=t}^{\infty} \beta^{j-t}\left[w_{j}-\varphi\left(h_{j}, h_{j+1} ; H\right)\right] \geq J\left(h_{t}\right), \quad \text { for } t \geq 0 \\
& -\tau h_{1}-w_{0}-k_{1}+\sum_{t=1}^{\infty} \beta^{t}\left[\pi\left(h_{t}, k_{t}, h_{t+1}\right)-w_{t}-k_{t+1}\right] \geq 0 \\
& h_{t+1}=f\left(h_{t}\right), \quad \text { for } t>0
\end{aligned}
$$

Notice that only the initial knowledge $h_{1}$ is chosen in this problem. Future values are determined by the investment policy of future new firms, that is, $h_{t+1}=f\left(h_{t}\right)$. We have not included the enforcement constraint after the investment in knowledge since it is already imbedded in $f\left(h_{t}\right)$.

The solution to this problem involves a non-trivial fixed point problem. First, as with the previous problem, the enforcement constraints involve the outside value $J\left(h_{t}\right)$, which is derived from the optimization problem solved by a new firm. Second, the policy function $f\left(h_{t}\right)$, which is taken as given by an incumbent firm, is also the policy function obtained as the solution of the same optimization problem. Solving for endogenous participation constraints is relatively new in the literature since they are often imposed exogenously by assuming autarky values.

A detailed characterization of the solution is given in Appendix E. It should be noticed that conditions (11) and (12) derived in the environment 
with investor's commitment, are also valid in the case with double-side limited commitment. The optimality condition for the accumulation of knowledge, however, is different. For new firms this is given by:

$$
\begin{array}{r}
\tau+\varphi_{2}\left(h_{t}, h_{t+1} ; H\right)=\beta\left\{\pi_{1}\left(h_{t+1}, k_{t+1}, f\left(h_{t+1}\right)\right)-\varphi_{1}\left(h_{t+1}, f\left(h_{t+1}\right) ; H\right)\right. \\
\left.+\left[\pi_{3}\left(h_{t+1}, k_{t+1}, f\left(h_{t+1}\right)\right)+\tau\right] f_{1}\left(h_{t+1}\right)\right\}(20)
\end{array}
$$

For incumbent firms there is no optimality condition for the investment in knowledge since they take as given the investment policy $f\left(h_{t}\right)$.

Imposing the steady state conditions $h_{t}=h_{t+1}=H$ and $k_{t}=k_{t+1}=K$, conditions (12) and (20) become:

$$
\begin{aligned}
\beta \pi_{2}(H, K, H)=1 & \\
\tau+\varphi_{2}(H, H ; H)=\beta\left\{\pi_{1}(H,\right. & K, f(H))-\varphi_{1}(H, f(H) ; H) \\
& \left.+f_{1}(H)\left[\pi_{3}(H, K, f(H))+\tau\right]\right\}
\end{aligned}
$$

Differently from the case in which the investor commits to the contract, these two conditions are no longer sufficient to determine the steady state values of $H$ and $K$. The unknown function $f(H)$ also need to be determined. This requires us to solve for a fixed point problem. Denote by $h^{\prime}=\psi(h ; f)$ the policy function that solves problem (19), for given $f$. The policy function satisfies the first order condition (20) and in equilibrium $f(H)=\psi(H ; f)$.

Because incumbent firms innovate at the same rate as new firms, condition (20) also determines the investment in knowledge of incumbent firms. Therefore, in order to determine whether the lack of commitment leads to higher or lower investment in knowledge, we have to compare condition (20) to the optimality condition for the investment in knowledge when the investor commits to the long-term contract, that is, condition (14).

Let $H^{C}$ be the steady state knowledge in the economy in which the investor commits, and $H^{N C}$ the steady state knowledge without commitment. We then have the following proposition: 
Proposition 4 Suppose that $f_{1}(H) \leq 1$. Then the steady state value of $H^{N C}$ is strictly decreasing in $\tau$ and there exists $\bar{\tau}>0$ such that $H^{N C}>H^{C}$ for $\tau<\bar{\tau}$ and $H^{N C}<H^{C}$ for $\tau>\bar{\tau}$.

Proof 4 See Appendix F.

Notice that the proof is based on the assumption that $f_{1}(H) \leq 1$, that is, the derivative of the policy function at the steady state equilibrium is not greater than one. We have checked this condition numerically. Therefore, when contracts are not enforceable for both parties, neither for the innovator nor for the investor, the start-up cost is harmful for the accumulation of knowledge. With low barriers, the economy experiences a higher level of income than in the economy with commitment. This could be welfare improving if there are spillovers in the accumulation of knowledge.

\section{Quantitative application}

In this section we use the model to quantify the contribution of the cost of business start-up to generate cross-country income inequality. In the quantitative application we focus on the 'cost of business start-up' because of data availability. It should be clear, however, that our theory is more general and applies to other barriers that affect the mobility of knowledge.

We calibrate the economy to the United States and then we ask how much of the cross-country income gaps from the United States can be accounted by the observed cost of business start-up. The discount factor, $\beta$, the production parameter, $\alpha$, and the depreciation parameter, $\delta$, are calibrated to replicate the following moments: an interest rate of 5 percent, a capital income share of 33 percent and a capital-output ratio of 3 . This implies $\beta=0.9524$, $\alpha=0.33$ and $\delta=0.06$. Notice that the three moments are invariant to the entry barrier $\tau$, and therefore, they are constant across countries. ${ }^{7}$

\footnotetext{
${ }^{7}$ While it is easy to see the mapping between the first two moments and the first two parameters $(\beta=1 /(1+r)$ and $\alpha=r K / Y)$, less obvious is the mapping between $\delta$ and the capital-income ratio. From condition(12), evaluated at the steady, we have $\beta \pi_{2}(H, K, H)=\beta\left[1-\delta+\alpha(K / H)^{\alpha-1}\right]=1$. Given the output function $Y=H^{1-\alpha} K^{\alpha}$, the capital-output ratio can be written as $K / Y=(K / H)^{1-\alpha}$. Using this expression to eliminate $K / H$ in the previous condition we get $\beta[1-\delta+\alpha /(K / Y)]=1$. Therefore, after choosing $\beta$ and $\alpha$, the parameter $\delta$ is uniquely determined by the capital-output ratio.
} 
The effort cost function is derived from the accumulation equation for the stock of knowledge, which is assumed to take the form:

$$
h_{t+1}=(1-\phi) h_{t}+\left(H_{t}^{\theta} e_{t}^{1-\theta}\right)^{\nu}
$$

where $H_{t}$ is the average level of knowledge, $e_{t}$ is the effort cost to accumulate knowledge and $\phi$ is the depreciation rate. The parameter $\nu<1$ captures the return to scale in the accumulation of knowledge and $\theta<1$ the leakage or spillover effects. Inverting we get the cost function:

$$
e_{t}=\varphi\left(h_{t}, h_{t+1} ; H_{t}\right)=\frac{\left[h_{t+1}-(1-\phi) h_{t}\right]^{\frac{1}{(1-\theta) \nu}}}{H_{t}^{\frac{\theta}{1-\theta}}}
$$

which is homogeneous of degree $\rho=(1-\theta \nu) /(1-\theta) \nu$.

The depreciation of knowledge results from working directly with the stationary version of the model, detrended by the rate of worldwide knowledge. The parameter $\phi$ is then approximately equal to the exogenous rate of growth. ${ }^{8}$ Assuming that the economy grows at 1.8 percent per year, we set $\phi=0.018$. This is about the average growth rate in per-capita GDP experience by the US during the last century.

The values of the other two parameters, $\theta$ and $\nu$, are more controversial. Manuelli \& Seshadri (2005) uses a similar specification of the investment function, within an overlapping generation model, but without externalities. In order to generate some key properties of the life-time profile of earnings, they choose a return to scale of 0.93 . This is also the value estimated by Heckman, Lochner, \& Taber (1998). We use this value to calibrate $\nu$ based on the assumption that there is sufficient intergenerational transmission of human capital. ${ }^{9}$ For the baseline parametrization we assume no externalities,

\footnotetext{
${ }^{8}$ The original (undetrended) function for the accumulation of knowledge is $h_{t+1}=h_{t}+$ $\bar{H}_{t}^{1-\nu}\left(H_{t}^{\theta} e_{t}^{1-\theta}\right)^{\nu}$, where $\bar{H}_{t}$ is the worldwide knowledge, external to an individual country, which grows at the constant rate $\bar{g}$. Normalizing all terms by $\bar{H}_{t}$, the investment function becomes $h_{t+1}=(1-\phi) h_{t}+A\left(H_{t}^{\theta} e_{t}^{1-\theta}\right)^{\nu}$, where $\phi=\bar{g} /(1+\bar{g}) \simeq \bar{g}$ and $A=1 /(1+\bar{g})$. Because $A$ acts as a rescaling factor, we can set $A=1$.

${ }^{9}$ In Manuelli \& Seshadri (2005) the cost of human capital investment has two components: time and expenditures. Our specification does not distinguish between these components and the investment cost is captured by the single variable $e$. However, this does not alter in important ways the main properties of the model. As Manuelli and Seshadri show, the key parameter to replicate the life-time earning profile is not the relative importance of the two inputs but the return to scale parameter. Notice that the depreciation rate $\phi=0.018$ is also equal to the value chosen by Manuelli and Seshadri.
} 
that is, $\theta=0$, which is the predominant assumption in the applied literature. The sensitivity analysis will clarify the importance of these two parameters.

\subsection{Results}

Figure 2 plots the values of per-capita GDP and start-up costs for different countries, and the values predicted by the model. As can be seen from the figure, the cost of business start-up captures a substantial amount of crosscountry income variability.

Figure 2: Cost of business start-up and output per-capita - Data and model.

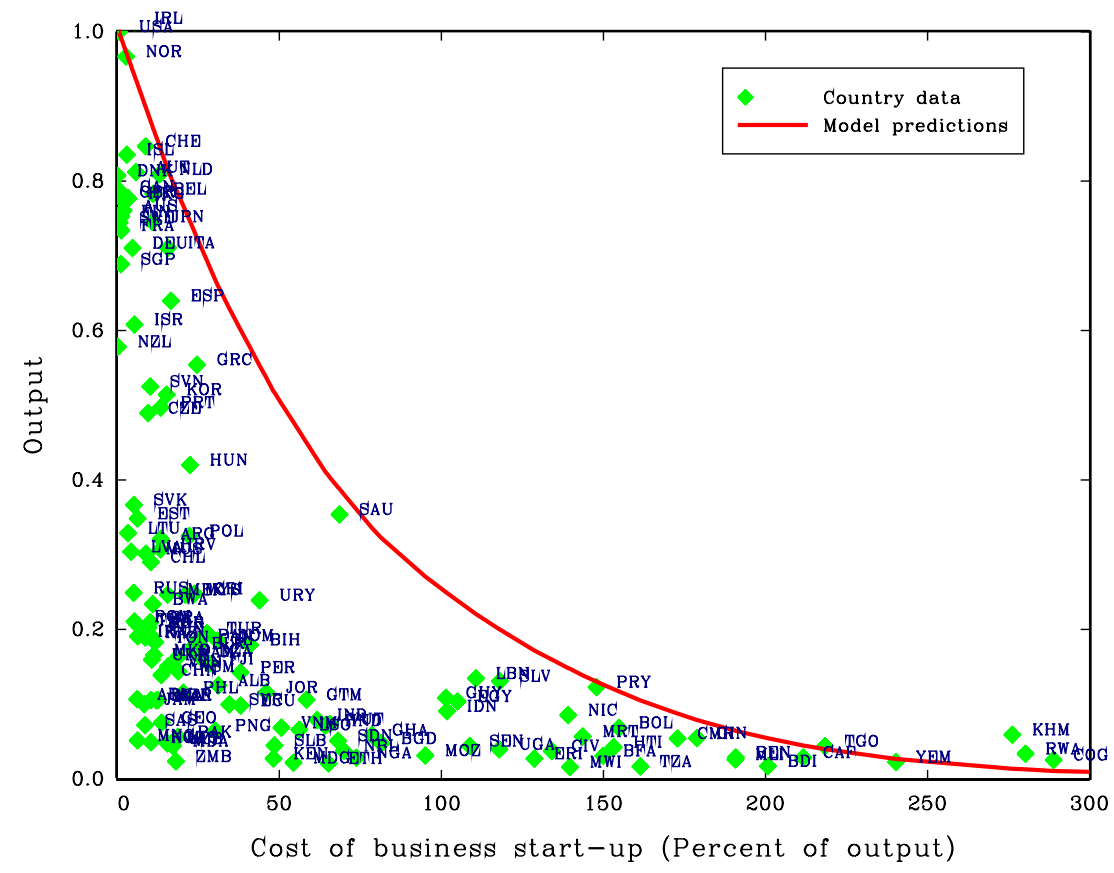

To compute the average cross-country income gap from the US captured by the model, we compute the following index:

$$
\text { Index }=1-\frac{\sum_{i}\left|\hat{y}_{i}-y_{i}\right|}{\sum_{i}\left|y_{U S}-y_{i}\right|}
$$

where $y_{i}$ is the actual income of country $i, \hat{y}_{i}$ is the income predicted by the model, given the observed cost of business start-up, and $y_{U S}$ is the US 
income. The model has been normalized so that it replicates the US income, that is, $\hat{y}_{U S}=y_{U S}$. The index is 1 if the model replicates perfectly the actual cross-country incomes, that is, $\hat{y}_{i}=y_{i}$. It is zero if the cost of business start-up has no impact on the equilibrium income, that is, $\hat{y}_{i}=y_{U S}$. For the baseline calibration the index is 0.51 . Therefore, the model accounts for about half of the cross-country income gap from the US.

Next we show the sensitivity of the results to $\nu$ and $\theta$. Table 2 reports the average income gap accounted by the model for alternative values of these parameters. The model captures a higher proportion of gaps when the return to scale is high and the externality is low. The results are especially sensitive to the return to scale parameter. When $\nu$ is close to 1 , the model generates about 70 percent of the income gaps. In the limiting case of constant returns, as in Lucas (1988) and Jovanovic (2004), there would be persistent growth differences (endogenous growth), and therefore, unbounded gaps. But even for small returns to scale, as in Parente \& Prescott (2002) where $\nu=0.6$, the model accounts for a non-negligible fraction of cross-country income gaps (about 10 percent).

Table 2: Average income gap accounted by the model.

\begin{tabular}{c|ccccccc}
\hline & \multicolumn{7}{|c}{ Value of $\nu$} \\
\hline \multirow{2}{*}{$\begin{array}{c}\text { Value of } \theta \\
0.0\end{array}$} & 0.97 & 0.93 & 0.90 & 0.80 & 0.70 & 0.60 \\
0.1 & 0.68 & $\mathbf{0 . 5 1}$ & 0.42 & 0.26 & 0.18 & 0.13 \\
0.2 & 0.66 & 0.48 & 0.40 & 0.25 & 0.17 & 0.12 \\
0.3 & 0.64 & 0.46 & 0.37 & 0.23 & 0.15 & 0.11 \\
0.4 & 0.62 & 0.43 & 0.35 & 0.21 & 0.14 & 0.10 \\
& 0.59 & 0.40 & 0.32 & 0.19 & 0.12 & 0.09 \\
\hline
\end{tabular}

We have also calculated the 'socially optimal' steady state level of output, that is, the output resulting from solving the planner's problem. This differs from the competitive output because of the externality. The steady state values of $H$ and $K$ in the planner allocation are found by solving the first 
order conditions:

$$
\begin{aligned}
& \beta \pi_{2}(H, K, H)=1 \\
& \varphi_{2}(H, H ; H)-\pi_{3}(H, K, H)=\beta\left[\pi_{1}(H, K, H)-\varphi_{1}(H, H ; H)\right. \\
& \left.-\varphi_{3}(H, H ; H)\right]
\end{aligned}
$$

These are similar to conditions (15) and (16) except for the additional term $\varphi_{3}(H, H ; H)$ in the second equation. This term captures the externality taken into account by the planner but ignored by the atomistic agents.

Table 3 reports the 'competitive' output as a fraction of the 'socially optimal' output, when there are no barriers to entry. A value greater than 1 means that there is over-accumulation of knowledge compared to the socially optimal level. As expected, this arises when the splillovers are small or zero, that is, $\theta \simeq 0$. In this case moderate barriers to business start up would be welfare improving. On the other hand, values smaller than 1 mean that there is under-accumulation of knowledge, compared to the social optimum. In this case barriers to entry are always suboptimal while moderate subsidies could improve welfare. As can be seen from the table, the under-accumulation of knowledge arises for moderate spillovers.

Table 3: Steady state output when contracts are not enforceable and there are no barriers to entry. Numbers are relative to the socially optimal output.

\begin{tabular}{c|ccccccc}
\hline & \multicolumn{7}{|c}{ Value of $\nu$} \\
& 0.97 & 0.93 & 0.90 & 0.80 & 0.70 & 0.60 \\
\hline Value of $\theta$ & & & & & & \\
0.0 & 1.81 & 1.28 & 1.18 & 1.08 & 1.04 & 1.03 \\
0.1 & 0.80 & 0.92 & 0.95 & 0.99 & 1.00 & 1.00 \\
0.2 & 0.41 & 0.71 & 0.80 & 0.92 & 0.96 & 0.98 \\
0.3 & 0.25 & 0.58 & 0.70 & 0.88 & 0.94 & 0.97 \\
0.4 & 0.17 & 0.51 & 0.64 & 0.84 & 0.92 & 0.96 \\
\hline
\end{tabular}




\section{Covenants and other barriers to mobility}

Other barriers to the mobility of innovators may have a similar effect in our model as the cost of business start up. As we have discussed in the Introduction, even within a similar legal and economic environment-resulting in similar costs for business start up - there may be differences in other barriers. Covenants is one of them. A covenant which is ex-post enforced prevents the innovator from using the acquired knowledge if she moves to another firm.

A natural way to model non-competitive covenants is by assuming that a quitting innovator can use only a fraction $\xi$ of the accumulated knowledge in the new firm. This formulation also captures the case in which part of the knowledge can not be used by the innovator due to the enforcement of IPR if she does not have full control of the patent. To fix ideas, a more stringent enforcement of covenants (or IPRs) is captured by a lower fraction $\xi$.

To keep the presentation brief, we limit the analysis to the one-period model. The extension to the infinite horizon will follow the same logic as the analysis with entry costs. The problem solved by a new firm, started at the beginning of the period, can be written as:

$$
S\left(h_{0}\right)=\max _{h_{1}, k_{1}, w}\left\{-\varphi\left(h_{0}, h_{1}\right)-k_{1}+\left(\xi h_{1}\right)^{1-\alpha} k_{1}^{\alpha}\right\}
$$

\section{s.t.}

$$
\begin{gathered}
w-\varphi\left(h_{0}, h_{1}\right) \geq D\left(h_{0}\right) \\
-w-k_{1}+\left(\xi h_{1}\right)^{1-\alpha} k_{1}^{\alpha} \geq 0
\end{gathered}
$$

The problem solved by an incumbent firm is as in problem (1). The first order conditions with respect to $h_{1}$, for incumbent and new firms, are:

$$
\begin{aligned}
& (1-\alpha)\left(\frac{k_{1}}{h_{1}}\right)^{\alpha}=\varphi_{h_{1}}\left(h_{0}, h_{1}\right)+\delta \cdot\left(\frac{k_{0}}{h_{0}}\right) \\
& (1-\alpha)\left(\frac{k_{1}}{h_{1}}\right)^{\alpha}=\varphi_{h_{1}}\left(h_{0}, h_{1}\right) \cdot \xi^{\alpha-1}
\end{aligned}
$$

Because $\xi<1$ and $\alpha<1$, the term $\xi^{\alpha-1}>1$. Therefore, the noncompeting covenants have the effect of increasing the cost of accumulating knowledge and acts similarly to the entry cost $\tau$. Proposition 1 becomes: 
Proposition 5 The knowledge investment of a new firm $h^{\text {New }}$ is strictly increasing in $\xi$ and there exists $\bar{\xi}>0$ such that $h^{\text {New }}=h^{\text {Old }}$.

Proof 5 Using the first order condition for the choice of physical capital, which is $\alpha\left(k_{1} / h_{1}\right)^{\alpha-1}=1$ for both incumbent and new firms, the above first order conditions can be rewritten as:

$$
\begin{aligned}
& (1-\alpha) \alpha^{\frac{\alpha}{1-\alpha}}=\varphi_{h_{1}}\left(h_{0}, h^{\text {Old }}\right)+\delta \cdot\left(\frac{k_{0}}{h_{0}}\right) \\
& (1-\alpha) \alpha^{\frac{\alpha}{1-\alpha}}=\varphi_{h_{1}}\left(h_{0}, h^{\text {New }}\right) \xi^{-1}
\end{aligned}
$$

The proposition follows directly from these two conditions.

Q.E.D.

All the results obtained in Section 4 trivially extend to the case of covenants and other similar barriers to the mobility of knowledge.

\section{Conclusion}

We have developed a theory in which barriers to knowledge mobility affect the accumulation of knowledge, and therefore, the level of income and growth. The theory does not simply say that "competition enhances income and growth". It also shows that different forms of contract enforcement affect the relation between competition, innovation and growth. In particular, when both investors and innovators can not commit to long-term contracts, the rate of innovation is determined by those firms that value innovation the most, that is, start-up firms. As a result, high levels of innovation are associated with low barriers to knowledge mobility. This leads to an overaccumulation of knowledge which is suboptimal at the firm level but could be welfare improving if there are spillovers.

In a semi-endogenous growth model we have shown that barriers to business start-up have the potential to explain significant cross-country income differences. This is the first step to bring our theory to the data. We also show that other barriers to knowledge mobility, such as strict enforcement of Covenants or Intellectual Property Rights, can have similar effects, suggesting a wide scope for the empirical application of the theory. 


\section{Appendix}

\section{A Proof of Proposition 2}

We show that, if there is a positive measure of firms adopting the policy $h_{1}=H_{1}^{\text {Old }}$, then each of these firms will renegotiate the contract after the investment in knowledge. Because in the second stage there will be at leat one unemployed innovator with $h_{1}=h_{1}^{\text {Old }}$, incumbent firms can use this innovator to replace the current one and renegotiate the promised payments. Anticipating this, an innovators will stay only if the firm agrees on $h_{1}=h_{1}^{\text {New }}$.

The next step is to show whether an individual firm deviates from the policy $h_{1}=h_{1}^{\text {New }}$ when all firms adopt this policy. In this case there are no innovators with $h_{1}=h_{1}^{\text {Old }}$ in the second stage, after the investment in knowledge. Because of this, an individual firm is able to adopt the optimal policy $h_{1}=h_{1}^{\text {Old }}$ because all the potential replacements have $h_{1}=h_{1}^{\text {New }}$. Two cases are possible. If $h_{1}^{\text {New }}<h_{1}^{\text {Old }}$, then none of the available replacements have the skills to run the new technology. If $h_{1}^{N e w}>h_{1}^{\text {Old }}$, the replacements have the ability to run the technology associated with $h_{1}^{\text {Old }}$. However, they have to be paid more than the promised payment to the incumbent innovator. Therefore, the threat of renegotiation is not credible.

The only possible equilibrium is the one in which only one firm has $h_{1}=h_{1}^{\text {Old }}$. Because this is the only firm with $h_{1}=h_{1}^{\text {Old }}$, the absence of replacements with the same skills allows the firm to make credible promises to the innovator. At the same time, once there is one firm with $h_{1}=h_{1}^{\text {Old }}$, which provides a potential replacement, a second firm will be unable to make a credible promise for the implementation of the policy $h_{1}=h_{1}^{\text {Old }}$. This is enough to break the credibility of the promises made by the second firm. Because there is a continuum of firms, the deviating firm is of measure zero and its contribution to the aggregates is negligible. Q.E.D.

\section{B First order conditions with investor's commitment}

We first prove the following lemma:

Lemma 1 The enforcement constraint 'after' the investment in knowledge is satisfied if the enforcement constraint is satisfied 'before' the investment in knowledge.

Proof 1 The enforcement constraints can be rewritten as:

$$
\begin{aligned}
& \sum_{j=t}^{\infty} \beta^{j-t}\left[w_{j}-\varphi\left(h_{j}, h_{j+1} ; H\right)\right] \geq V\left(h_{t}\right) \\
& \sum_{j=t}^{\infty} \beta^{j-t}\left[w_{j}-\varphi\left(h_{j}, h_{j+1} ; H\right)\right] \geq-\varphi\left(h_{t}, h_{t+1} ; H\right)+\widehat{V}\left(h_{t+1}\right)
\end{aligned}
$$


Therefore, to show that the second constraint is satisfied when the first constraint is satisfied, it is enough to show that $V\left(h_{t}\right) \geq-\varphi\left(h_{t}, h_{t+1} ; H\right)+\widehat{V}_{t}\left(h_{t+1}\right)$ for any value of $h_{t+1}$. Because $V\left(h_{t}\right)=\max _{h}\left\{-\varphi\left(h_{t}, h ; H\right)+\widehat{V}(h)\right\}$, we have that:

$$
V\left(h_{t}\right)=\max _{h}\left\{-\varphi\left(h_{t}, h ; H\right)+\widehat{V}(h)\right\} \geq-\varphi\left(h_{t}, h_{t+1} ; H\right)+\widehat{V}\left(h_{t+1}\right)
$$

for any $h_{t+1}$.

Q.E.D.

Let's consider now problem (9). Thanks to the above lemma we can ignore the enforcement constraint after the investment in knowledge. Let $\gamma_{t}$ be the Lagrange multiplier associated with the enforcement constraint before the investment in knowledge and $\lambda_{0}$ the Lagrange multiplier associated with the participation constraint for the investor. The Lagrangian can be written as:

$$
\begin{aligned}
\mathcal{L} & =\sum_{t=0}^{\infty} \beta^{t}\left[w_{t}-\varphi\left(h_{t}, h_{t+1} ; H\right)\right] \\
& +\sum_{t=0}^{\infty} \beta^{t} \gamma_{t}\left\{\sum_{j=t}^{\infty} \beta^{j-t}\left[w_{j}-\varphi\left(h_{j}, h_{j+1} ; H\right)\right]-V_{t}\left(h_{t}\right)\right\} \\
& +\lambda_{0}\left\{-w_{0}-\tau h_{1}-k_{1}+\sum_{t=1}^{\infty} \beta^{t}\left[\pi\left(h_{t}, k_{t}, h_{t+1}\right)-w_{t}-k_{t+1}\right]\right\}
\end{aligned}
$$

Define $\mu_{t}$ recursively as follows: $\mu_{t+1}=\mu_{t}+\gamma_{t}$, with $\mu_{0}=0$. Using this variable and rearranging terms, the Lagrangian can be written as:

$$
\begin{aligned}
\mathcal{L}=\sum_{t=0}^{\infty} \beta^{t}\{(1+ & \left.\left.\mu_{t+1}\right)\left[w_{t}-\varphi\left(h_{t}, h_{t+1} ; H\right)\right]-\left(\mu_{t+1}-\mu_{t}\right) V\left(h_{t}\right)\right\} \\
& +\lambda_{0}\left\{-w_{0}-\tau h_{1}-k_{1}+\sum_{t=1}^{\infty} \beta^{t}\left[\pi\left(h_{t}, k_{t}, h_{t+1}\right)-w_{t}-k_{t+1}\right]\right\}
\end{aligned}
$$

This problem becomes recursive at any $t>0$. Therefore, we can rewrite the problem as follows:

$$
\begin{aligned}
\mathcal{L}=\min _{\mu_{1} \geq 0} \max _{\substack{w_{0} \geq 0, k_{1}, h_{1}}}\left\{\lambda_{0}\left[-w_{0}-\tau h_{1}-k_{1}\right]+\right. & \left(1+\mu_{1}\right)\left[w_{0}-\varphi\left(h_{0}, h_{1} ; H\right)\right] \\
& \left.-\mu_{1} V\left(h_{0}\right)+\beta W\left(\mu_{1}, h_{1}, k_{1}\right)\right\}
\end{aligned}
$$


with the function $W$ is defined recursively as follows:

$$
\begin{aligned}
& W\left(\mu_{t}, h_{t}, k_{t}\right)=\min _{\mu_{t+1} \geq \mu_{t}} \max _{\substack{w_{t} \geq 0, k_{t+1}, h_{t+1}}}\left\{\lambda_{0}\left[\pi\left(h_{t}, k_{t}, h_{t+1}\right)-w_{t}-k_{t+1}\right]\right. \\
& +\left(1+\mu_{t+1}\right)\left[w_{t}-\varphi\left(h_{t}, h_{t+1} ; H\right)\right] \\
& \left.-\left(\mu_{t+1}-\mu_{t}\right) V\left(h_{t}\right)+\beta W\left(\mu_{t+1}, h_{t+1}, k_{t+1}\right)\right\}
\end{aligned}
$$

for all $t>0$.

The first optimization problem (equation (26)) is the problem solved by a new firm with initial state $h_{0}$ and for a given $\lambda_{0}$. The lagrange multiplier $\lambda_{0}$ is determined such that the participation constraint for the investor is satisfied. Tighter is this constraint and higher is the value of $\lambda_{0}$. The second optimization problem (equation (27)) is the one solved after entering. Therefore, this is the problem solved by an incumbent firm that starts with states $\mu_{t}, h_{t}$ and $k_{t}$.

Taking derivatives in problem (26) gives:

$$
\begin{aligned}
& V\left(h_{t}\right) \leq-\varphi\left(h_{t}, h_{t+1} ; H\right)+w_{t}+\beta V\left(h_{t+1}\right) \\
& 1+\mu_{t+1} \leq \lambda_{0} \\
& \beta \pi_{2}\left(h_{t+1}, h_{t+1}, k_{t+1}\right)=1 \\
& \lambda_{0} \tau+\left(1+\mu_{t+1}\right) \varphi_{2}\left(h_{t}, h_{t+1} ; H\right)=\beta W_{2}\left(\mu_{t+1}, h_{t+1}, k_{t+1}\right)
\end{aligned}
$$

for $t=0$ and with the envelope term given by:

$$
W_{2}\left(\mu_{t}, h_{t}, k_{t}\right)=\lambda_{0} \pi_{1}\left(h_{t}, k_{t}, h_{t+1}\right)-\left(1+\mu_{t+1}\right) \varphi_{1}\left(h_{t}, h_{t+1} ; H\right)-\left(\mu_{t+1}-\mu_{t}\right) V_{1}\left(h_{t}\right)
$$

The first order conditions in problem (27) are (28)-(30) and

$$
-\lambda_{0} \pi_{3}\left(h_{t}, k_{t}, h_{t+1}\right)+\left(1+\mu_{t+1}\right) \varphi_{2}\left(h_{t}, h_{t+1} ; H\right)=\beta W_{2}\left(\mu_{t+1}, h_{t+1}, k_{t+1}\right)
$$

As emphasized above, the value of $\lambda_{0}$ depends on the tightness of the participation constraint for the investor. Assume that a new firm can choose $h_{1}<h_{0}$ without any cost. This is equivalent to assuming that the innovator choose to destroy part of the knowledge. Then we can prove that the investor is able to break even if the contract chooses the unconstrained sequence of $h$. This implies that $\lambda_{0}=1$ and, from condition (29), $\mu_{t}=0$ for all $t$. Using this and substituting the envelope term, conditions (28), (30), (31) and (32) become (11)-(14). Q.E.D. 


\section{Steady state equilibrium when the investor commits}

Proposition 6 There is a unique steady state equilibrium in which all firms have the same knowledge $H$ and physical capital $K$.

Proof 6 Consider condition (16), which we rewrite here as follows:

$$
\varphi_{2}(H, H ; H)+\beta \varphi_{1}(H, H ; H)=\pi_{3}(H, K, H)+\beta \pi_{1}(H, K, H)
$$

The right-hand-side term remains constant for any value of $H$. In fact, taking into account the functional form of $\pi$ (see equation (8)), we have that $\pi_{3}(H, K, H)=$ $-\delta(K / H)$ and $\pi_{1}(H, K, H)=\delta(K / H)+(1-\alpha)(K / H)^{\alpha}$. These two terms only depend on the ratio $K / H$. From condition (15) we have that $\beta \pi_{2}(H, K, H)=$ $\beta\left[1+\alpha(K / H)^{\alpha-1}\right]=1$, which uniquely determines the ratio $K / H$.

Let's look now at the left-hand-side term. Because $\varphi$ is homogenous of degree $\rho>1$, the derivatives $\varphi_{1}$ and $\varphi_{2}$ are homogeneous of degree $\rho-1$. Therefore, the left-hand-side term can be written as

$$
\varphi_{2}(H, H ; H)+\beta \varphi_{1}(H, H ; H)=\left[\varphi_{2}(1,1 ; 1)+\beta \varphi_{1}(1,1 ; 1)\right] H^{\rho-1}
$$

Because $\rho>1$, this term is strictly increasing in $H$, converges to zero as $H \rightarrow 0$ and to infinity as $H \rightarrow \infty$. Therefore, there exists a unique value of $H$ that solves this condition. The uniqueness of $H$ then implies the uniqueness of K. Q.E.D.

\section{Proof of Proposition 3}

Suppose that the knowledge investment chosen by a new firm is different from the one chosen by an incumbent firm. Denote by $h_{t+1}^{\text {New }}$ and $h_{t+1}^{\text {Old }}$ the investment of new and incumbent firms, respectively. Because $h_{t+1}^{\text {New }}$ solves the problem $V_{t}\left(h_{t}\right)=$ $\max _{h_{t+1}}\left\{-\varphi\left(h_{t}, h_{t+1} ; H\right)+\widehat{V}_{t}\left(h_{t+1}\right)\right\}$, we have that:

$$
V_{t}\left(h_{t}\right)>-\varphi\left(h_{t}, h_{t+1}^{\text {Old }} ; H\right)+\widehat{V}_{t}\left(h_{t+1}^{\text {Old }}\right)
$$

if $h_{t+1}^{\text {Old }} \neq h_{t+1}^{N e w}$. But then constraints (17) and (18) cannot be both satisfied. Therefore, the only feasible solution is $h_{t+1}=h_{t+1}^{N e w}$. Q.E.D. 


\section{E Derivation of the first order condition (20)}

Following the same steps of Appendix B, we can show that in a steady state equilibrium, problem (19) can be reformulated as:

$$
\begin{aligned}
\mathcal{L}=\min _{\mu_{1} \geq 0} \max _{\substack{w_{0} \geq 0, k_{1}, h_{1}}}\left\{\lambda_{0}\left[-w_{0}-\tau h_{1}-k_{1}\right]+\right. & \left(1+\mu_{1}\right)\left[w_{0}-\varphi\left(h_{0}, h_{1} ; H\right)\right] \\
& \left.-\mu_{1} J\left(h_{0}\right)+\beta W\left(\mu_{1}, h_{1}, k_{1}\right)\right\}
\end{aligned}
$$

with the function $W$ is defined recursively as follows:

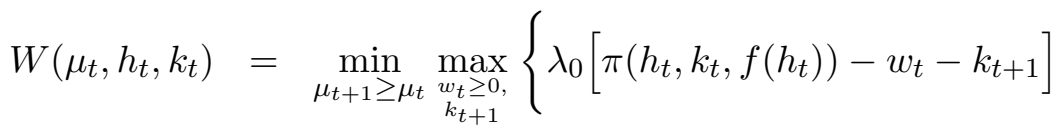

$$
\begin{aligned}
& +\left(1+\mu_{t+1}\right)\left[w_{t}-\varphi\left(h_{t}, f\left(h_{t}\right) ; H\right)\right] \\
& \left.-\left(\mu_{t+1}-\mu_{t}\right) J\left(h_{t}\right)+\beta W\left(\mu_{t+1}, f\left(h_{t}\right), k_{t+1}\right)\right\}
\end{aligned}
$$

for all $t>0$.

The first order condition with respect to $h_{1}$ in problem (33) gives:

$$
\lambda_{0} \tau+\left(1+\mu_{1}\right) \varphi_{2}\left(h_{0}, h_{1} ; H\right)=\beta W_{2}\left(\mu_{1}, h_{1}, k_{1}\right)
$$

with the envelope condition given by:

$$
\begin{aligned}
W_{2}\left(\mu_{t}, h_{t}, k_{t}\right)= & \lambda_{0} \pi_{1}\left(h_{t}, k_{t}, f\left(h_{t}\right)\right)+\lambda_{0} \pi_{3}\left(h_{t}, k_{t}, f\left(h_{t}\right)\right) f_{1}\left(h_{t}\right) \\
& -\left(1+\mu_{t+1}\right) \varphi_{1}\left(h_{t}, f\left(h_{t}\right) ; H\right)-\mu_{t+1} \varphi_{2}\left(h_{t}, f\left(h_{t}\right) ; H\right) f_{1}\left(h_{t}\right) \\
& -\left(\mu_{t+1}-\mu_{t}\right) J_{1}\left(h_{t}\right)+\beta W_{2}\left(\mu_{t+1}, h_{t+1}, k_{t+1}\right) f_{1}\left(h_{t}\right)
\end{aligned}
$$

With limited enforcement, condition (35) must be satisfied at any point in time. Substituting this condition in (36), we get:

$$
\begin{aligned}
W_{2}\left(\mu_{t}, h_{t}, k_{t}\right)= & \lambda_{0} \pi_{1}\left(h_{t}, k_{t}, f\left(h_{t}\right)\right)-\left(1+\mu_{t+1}\right) \varphi_{1}\left(h_{t}, f_{t}\left(h_{t}\right) ; H\right) \\
& -\left(\mu_{t+1}-\mu_{t}\right) J_{1}\left(h_{t}\right)+\lambda_{0}\left[\pi_{3}\left(h_{t}, k_{t}, f\left(h_{t}\right)\right)+\tau\right] f_{1}\left(h_{t}\right)
\end{aligned}
$$

Also in this case we can prove that the unconstrained investment in knowledge capital allows the investor to break-even. Therefore, $\lambda_{0}=1$ and $\mu_{t}=0$. Using this result and substituting the envelope in (35) we get condition (20). Q.E.D. 


\section{F Proof of Proposition 4}

In the steady state without commitment, potential new firms start with the same knowledge $H$ as incumbents firms. Because $H=f(H)$, condition $(22)$ can be written as:

$$
\tau+\varphi_{2}(H, H ; H)=\beta\left[\pi_{1}(H, K, H)-\varphi_{1}(H, H ; H)\right]+\beta f_{1}(H)\left[\pi_{3}(H, K, H)+\tau\right]
$$

which determines the steady state knowledge for incumbent and new firms when the investor does not commit (double-side limited enforcement).

This condition must be compared to the optimality condition that determines the steady state knowledge when the investor commits to the contract (one-side limited enforcement). This is given by equation (16), which we rewrite as:

$$
\varphi_{2}(H, H ; H)=\beta\left[\pi_{1}(H, K, H)-\varphi_{1}(H, H ; H)\right]+\pi_{3}(H, K, H)
$$

The homogeneity of degree $\rho$ of the cost function $\varphi$ implies that the derivatives are homogeneous of degree $\rho-1$. Therefore, the above two conditions can be rewritten as:

$$
\begin{aligned}
{\left[\varphi_{2}(1,1 ; 1)+\beta \varphi_{1}(1,1 ; 1)\right] H^{\rho-1} } & =\beta \pi_{1}(H, K, H)+\beta f_{1}(H) \pi_{3}(H, K, H) \\
& -\tau\left[1-\beta f_{1}(H)\right] \\
{\left[\varphi_{2}(1,1 ; 1)+\beta \varphi_{1}(1,1 ; 1)\right] H^{\rho-1} } & =\beta \pi_{1}(H, K, H)+\pi_{3}(H, K, H)
\end{aligned}
$$

Because $\rho-1>0$, the left-hand-side terms are strictly increasing in $H$, converge to zero as $H \rightarrow 0$ and to infinity as $H \rightarrow \infty$. We further observe that, as shown in the proof of Proposition 6 , the terms $\pi_{1}$ and $\pi_{3}$ only depend on the ratio $K / H$. This term is uniquely pinned down by condition (12), which is the same for both economies. Therefore, $\pi_{1}(H, K, H)$ and $\pi_{3}(H, K, H)$ do not change as $H$ changes.

Consider first the case in which the start-up cost is zero, that is, $\tau=0$. If $f_{1}(H) \leq 1$, as postulated in the proposition, the term $\beta f_{1}(H)<1$. Because $\pi_{3}(H, K, H)<0$ and $\beta f_{1}(H)<1$, the right-hand-side of $(37)$ is bigger than the right-hand-side of (38) for a given $H$. This implies that the value of $H$ in the first equation must be bigger than in the second, that is, $H^{N C}>H^{C}$. Notice that, without capital obsolescence, $\pi_{3}(H, K, H)=0$. Therefore, conditions (37) and (38) are indistinguishable if $\tau=0$.

Let's consider now the case in which $\tau>0$. This variable only affects condition (37). Because $\beta f_{1}(H)<1$, then an increase in $\tau$ reduces the right-hand-side of (37). The reduction in the left-hand-side term then requires a lower value of $H$. For a sufficiently large $\tau$, the steady state level of knowledge declines to the point in which $H^{N C}<H^{C}$.

Q.E.D. 


\section{G The role of barriers when the probability of survival is $p<1$}

We keep the assumption that the survival of the firm is observed after the investment in knowledge. Therefore, the level of $h_{t+1}$ is predetermined for new firms. The physical capital, however, is chosen after the realization of survival. This is not essential for the properties of the equilibrium but it simplifies its characterization.

If an incumbent firm survives, the innovator receives $w_{t}$ and stays with the current employer. If the firm exits, the innovator is hired by a new firm and receives the lifetime utility $\widehat{V}\left(h_{t+1}\right)$. We can then define the pseudo utility flow for the innovator as follows:

$$
U\left(h_{t}, h_{t+1}, w_{t} ; H\right) \equiv-\varphi\left(h_{t}, h_{t+1} ; H\right)+p w_{t}+(1-p) \widehat{V}\left(h_{t+1}\right)
$$

The contracting problem with investor's commitment is similar to (9) after making the following changes: the term $w_{t}-\varphi\left(h_{t}, h_{t+1} ; H\right)$ is replaced with $U\left(h_{t}, h_{t+1}, w_{t} ; H\right)$; future flows are discounted by $p \beta$; the firm pays $w_{t}+k_{t+1}$ only in case of survival.

After making these changes, we repeat the steps used in Appendix B for the case with $p=1$. The first order conditions for a new firm at $t=0$ are:

$$
\begin{aligned}
& V\left(h_{t}\right) \leq-\varphi\left(h_{t}, h_{t+1} ; H\right)+p w_{t}+(1-p) \widehat{V}\left(h_{t+1}\right)+p \beta V\left(h_{t+1}\right) \\
& 1+\mu_{t+1} \leq \lambda_{0} \\
& \beta \pi_{2}\left(h_{t+1}, k_{t+1}, h_{t+1}\right)=1 \\
& \lambda_{0} \tau+\left(1+\mu_{t+1}\right) \varphi_{2}\left(h_{t}, h_{t+1} ; H\right)= \\
& \quad\left(1+\mu_{t+1}\right)(1-p) \widehat{D}_{1}\left(h_{t+1}\right)+p \beta W_{2}\left(\mu_{t+1}, h_{t+1}, k_{t+1}\right)
\end{aligned}
$$

with the envelope term given by:

$$
W_{2}\left(\mu_{t}, h_{t}, k_{t}\right)=\lambda_{0} \pi_{1}\left(h_{t}, k_{t}, h_{t+1}\right)-\left(1+\mu_{t+1}\right) \varphi_{1}\left(h_{t}, h_{t+1} ; H\right)-\left(\mu_{t+1}-\mu_{t}\right) V_{1}\left(h_{t}\right)
$$

The first order conditions for $t>0$ (incumbent firm) are (39)-(41) and

$$
\begin{aligned}
& -\lambda_{0} \pi_{3}\left(h_{t}, k_{t}, h_{t+1}\right)+\left(1+\mu_{t+1}\right) \varphi_{2}\left(h_{t}, h_{t+1} ; H\right)= \\
& \left(1+\mu_{t+1}\right)(1-p) \widehat{V}_{1}\left(h_{t+1}\right)+p \beta W_{2}\left(\mu_{t+1}, h_{t+1}, k_{t+1}\right)
\end{aligned}
$$

Also in this case the investor breaks even when the contract chooses the unconstrained knowledge. Therefore, $\lambda_{0}=1$ and $\mu_{t}=0$. With all $\mu$ set to 0 , the function $W$ is the surplus generated by an incumbent firm. Using this, the sur-

plus generated by a new firm, after the investment in knowledge and after the realization of survival, can be written as:

$$
\widehat{V}\left(h_{t}\right)=-\tau h_{t+1}-k_{t+1}-w_{t}+\beta W\left(1, h_{t+1}, k_{t+1}\right)
$$


from which we have $\widehat{V}_{1}\left(h_{t+1}\right)=-\tau+\beta W_{2}\left(1, h_{t+1}, k_{t+1}\right)$. Therefore, conditions (42) and (43) can be rewritten as:

$$
\begin{aligned}
& \left.(1-p) \tau+\tau+\varphi_{2}\left(h_{t}, h_{t+1} ; H\right)=\beta\left[\pi_{1}\left(h_{t+1}, k_{t+1}, h_{t+2}\right)-\varphi_{1}\left(h_{t+1}, h_{t+2} ; H\right)\right] 44\right) \\
& (1-p) \tau-\pi_{3}\left(h_{t}, k_{t}, h_{t+1}\right)+\varphi_{2}\left(h_{t}, h_{t+1} ; H\right)=\beta\left[\pi_{1}\left(h_{t+1}, k_{t+1}, h_{t+2}\right)\right. \\
& \left.-\varphi_{1}\left(h_{t+1}, h_{t+2} ; H\right)\right]
\end{aligned}
$$

The conditions for the accumulation of knowledge when the investor commits to the contract are similar to the corresponding conditions derived earlier (see (13) and (14)), with the exception of the constant term $(1-p) \tau$. The most important difference respect to the case with $p=1$ is that now the entry cost affects negatively the steady state value of $H$ even if the investor commits to the contract.

Higher values of $p$ (higher survival) increase the steady state value of knowledge because it reduces the term $(1-p) \tau$. This corresponds to a reduction in the marginal cost of accumulating knowledge for both new and incumbent firms.

When both parties are unable to commit, the optimization problem can be written as in (19), once we replace $w_{t}-\varphi\left(h_{t}, h_{t+1} ; H\right)$ with $U\left(h_{t}, h_{t+1}, w_{t} ; H\right)$, discount future flows by $p \beta$, and take into account that the firm pays $w_{t}+k_{t+1}$ only in case of survival. The first order condition for the accumulation of knowledge of a new firm $(t=0)$ can be written as:

$$
\begin{aligned}
& (1-p) \tau+\tau+\varphi_{2}\left(h_{t}, h_{t+1} ; H\right)=\beta\left\{\pi_{1}\left(h_{t+1}, k_{t+1}, f\left(h_{t+1}\right)\right)\right. \\
& \left.-\varphi_{1}\left(h_{t+1}, f\left(h_{t+1}\right) ; H\right)+f_{1}\left(h_{t+1}\right)\left[\pi_{3}\left(h_{t+1}, k_{t+1}, f\left(h_{t+1}\right)\right)+\tau\right]\right\}
\end{aligned}
$$

which differs from $(20)$ only in the constant term $(1-p) \tau$.

Let $H^{C}$ be the steady state level of knowledge when the investor commits and $H^{N C}$ the steady state level when the investor does not commit. Proposition 4 can be reformulated as follows:

Proposition 7 Assume $p \in(0,1)$. The steady state values of $H^{C}$ and $H^{N C}$ are both strictly decreasing in $\tau$. Moreover, there exists $\bar{\tau}>0$ such that $H^{N C}>H^{C}$ for $\tau<\bar{\tau}$ and $H^{N C}<H^{C}$ for $\tau>\bar{\tau}$.

Barriers to entry affect the accumulation of knowledge even when the investor commits to the contract. However, their negative impact is stronger with doubleside limited commitment. The proof of the proposition, which is omitted for economy of space, uses the same logic as in the proof of Proposition 4. 


\section{References}

Acemoglu, D. (1997). Training and innovation in an imperfect labor market. Review of Economic Studies, 64 (3), 445-64.

Acemoglu, D., Aghion, P., \& Zilibotti, F. (2002). Distance to frontier, selection, and economic growth. CEPR Discussion Paper \#3467.

Acemoglu, D. \& Pischke, J. (1999). The structure of wages and investment in general training. Journal of Political Economy, 107(3), 539-72.

Acemoglu, D. \& Shimer, R. (1999). Holdups and efficiency with search frictions. International Economic Review, 40(4), 827-50.

Aghion, P., Bloom, N., Blundell, R., Griffith, R., \& Howitt, P. (2005). Competition and innovation: an inverted U-relationship. Quarterly Journal of Economics, 120(2), 701-28.

Aghion, P., Blundell, R., Griffith, R., Howitt, P., \& Prantl, S. (2004). Firm entry, innovation and growth: theory and micro evidence. Unpublished manuscript. Institute for Fiscal Studies \& Harvard University.

Aghion, P. \& Griffith, R. (2005). Competition and Growth: Reconciling Theory and Evidence. MIT Press, Cambridge, Massachusetts.

Anton, J. J. \& Yao, D. A. (1994). Expropriation and inventions: appropriable rents in the absence of property rights. American Economic Review, 84(1), 190-209.

Baccara, M. \& Razin, R. (2004). Curb your innovation: corporate conservatism in the presence of imperfect intellectual property rights. Unpublished manuscript, New York University.

Boldrin, M. \& Levine, D. (2006). Against Intellectual Monopoly. Electronic version, http://www.econ.umn.edu/ mboldrin/aim.html.

Bresnahan, T. F. \& Malerba, F. (2002). The value of competitive innovation and U.S. policy toward the computer industry. In Bai, C.-E. \& Yuen, C.-W. (Eds.), Technology and the New Economy, chap. 2, pp. 49-93. MIT Press, Cambridge, Massachusetts. 
Cooley, T. F., Marimon, R., \& Quadrini, V. (2004). Aggregate consequences of limited contracts enforceability. Journal of Political Economy, 111(4), 421-46.

Gilson, R. J. (1999). The legal infrastructure of high technology industrial districts: silicon valley, route 128 , and covenants not to compete. New York University Law Review, 74(3), 575-629.

Greenwood, J. \& Jovanovic, B. (1990). Financial development, growth, and the distribution of income. Journal of Political Economy, 98(5), 10761107.

Heckman, J., Lochner, L., \& Taber, C. (1998). Explaining rising wage inequality: explorations with a dynamics general equilibrium model of labor earnings with heterogeneos agents. Review of Economic Dynamics, 1, 1-58.

Hyde, A. (2003). Working in Silicon Valley: Economic and Legal Analysis of a High-Velocity Labor Market. Sharpe, M.e., Inc., Armonk, New York.

Jones, C. I. (1995). R\&D - Based models of economic growth. Journal of Political Economy, 103(4), 759-84.

Jovanovic, B. (2004). The product cycle and inequality. Unpublished Manuscript, Department of Economics, New York University.

Kocherlachota, N. R. (1996). Implications of efficient risk sharing without commitment. Review of Economic Studies, 63(4), 595-609.

Lucas, R. E. (1988). On the mechanics of economic development. Journal of Monetary Economics, 22, 3-42.

Manuelli, R. \& Seshadri, A. (2005). Human capital and the wealth of nations. Unpublished manuscript, University of Wisconsin in Madison.

Marcet, A. \& Marimon, R. (1992). Communication, commitment and growth. Journal of Economic Theory, 58(1), 219-249.

Mokyr, J. (1990). The Lever of Riches: Technological Creativity and Economic Progress. Oxford University Press, New York. 
Parente, S. L. \& Prescott, E. C. (2002). Barriers to Riches. MIT Press, Cambridge, Massachusetts.

Romer, P. M. (1990). Endogenous technological change. Journal of Political Economy, 98(1), 71-102.

Romer, P. M. (1993). Two strategies for economic development: using ideas and producing ideas. World Bank Economic Review, 7(1), 63-91.

Saxenian, A. (1996). Regional Advantage: Culture and Competition in Silicon Valley and Route 128. Harvard University Press, Cambridge, Massachusetts.

World Bank (2005). Doing Business in 2005: Removing Obstacles to Growth. World Bank, Washington. 